\title{
HealthAffairs
}

At the Intersection of Health, Health Care and Policy

Cite this article as:

Thomas Hone, Davide Rasella, Mauricio Barreto, Rifat Atun, Azeem Majeed and Christopher Millett

Large Reductions In Amenable Mortality Associated With Brazil's Primary Care

Expansion And Strong Health Governance

Health Affairs 36, no.1 (2017):149-158

doi: 10.1377/hlthaff.2016.0966

The online version of this article, along with updated information and services, is available at:

http://content.healthaffairs.org/content/36/1/149

For Reprints, Links \&

Permissions : $\quad$ http://content.healthaffairs.org/1340_reprints.php

Email Alertings : http://content.healthaffairs.org/subscriptions/etoc.dtl

To Subscribe : https://fulfillment.healthaffairs.org

Health Affairs is published monthly by Project HOPE at 7500 Old Georgetown Road, Suite 600, Bethesda, MD 20814-6133. Copyright (C)

by Project HOPE - The People-to-People Health Foundation. As provided by United States copyright law (Title 17, U.S. Code), no part of may be reproduced, displayed, or transmitted in any form or by any means, electronic or mechanical, including photocopying or by information storage or retrieval systems, without prior written permission from the Publisher. All rights reserved. 


\section{Large Reductions In Amenable Mortality Associated With Brazil's Primary Care Expansion And Strong Health Governance}

ABSTRACT Strong health governance is key to universal health coverage. However, the relationship between governance and health system performance is underexplored. We investigated whether expansion of the Brazilian Estratégia de Saúde da Família (ESF; family health strategy), a community-based primary care program, reduced amenable mortality (mortality avoidable with timely and effective health care) and whether this association varied by municipal health governance. Fixed-effects longitudinal regression models were used to identify the relationship between ESF coverage and amenable mortality rates in 1,622 municipalities in Brazil over the period 2000-12. Municipal health governance was measured using indicators from a public administration survey, and the resulting scores were used in interactions. Overall, increasing ESF coverage from 0 percent to 100 percent was associated with a reduction of 6.8 percent in rates of amenable mortality, compared with no increase in ESF coverage. The reductions were $\mathbf{1 1 . 0}$ percent for municipalities with the highest governance scores and 4.3 percent for those with the lowest scores. These findings suggest that strengthening local health governance may be vital for improving health services effectiveness and health outcomes in decentralized health systems.

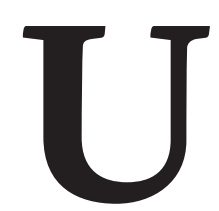
niversal health coverage is a priority for World Health Organization (WHO) member states ${ }^{1}$ and a target of the United Nations Sustainable Development Goals. ${ }^{2}$ However, the focus of policy makers and researchers concerned with extending universal health coverage has been on financing, benefit packages, and service coverage, with less emphasis on health systems governance.

The WHO asserts that universal health coverage cannot deliver anticipated health benefits in the absence of good governance. ${ }^{3}$ Governance can be defined as "the combination of political, social, economic and institutional factors that affect the behavior of organizations and individuals and that influence their performance." ${ }^{4}$ It includes the "steering and rule-making related functions carried out by governments." ${ }^{5}$

As a prerequisite for effective policy making, preserving local political commitment, and protecting the achievements of universal health coverage, strong health governance is essential for the implementation of universal health coverage. ${ }^{6}$ Health governance is considered to be central to the relationship between spending and improvements in health. ${ }^{7}$ Implementation of universal health coverage in many countries is decentralized to local agencies to promote the adaptation of services to local needs, increase accountability to citizens, and encourage the participation of local communities-with the aim of increasing service quality and efficiency. ${ }^{8-11}$ However, envisaged benefits are unlikely
DOI: $10.1377 /$ hlthaff.2016.0966 HEALTH AFFAIRS 36 , NO. 1 (2017): 149-158 ○2017 Project HOPEThe People-to-People Health Foundation, Inc.
Thomas Hone (thomas

.hone12@imperial.ac.uk) is a $\mathrm{PhD}$ student in the Public Health Policy Evaluation Unit, Department of Primary Care and Public Health, School of Public Health, at Imperial College London, in England, and a visiting scholar at the Harvard T. H. Chan School of Public Health, in Boston, Massachusetts.

Davide Rasella is a Wellcome Trust Research Fellow at the Centro de Pesquisas Gonçalo Muniz, Fundacão Oswaldo Cruz, in Salvador, Brazil.

Mauricio L. Barreto is a senior investigator at the Instituto Gonçalo Muniz, Fundação Oswaldo Cruz, and a professor at the Instituto de Saúde Coletiva, Universidade Federal da Bahia, in Brazil.

Rifat Atun is a professor of global health systems at Harvard University.

Azeem Majeed is a professor of primary care in the Department of Primary Care and Public Health, Imperial College London, and a primary care physician in London.

Christopher Millett is a professor of public health in the Department of Primary Care and Public Health, Imperial College London, and a visiting professor at the Center for Epidemiological Studies in Health and Nutrition, Universidade de São Paulo, and in the Department of Epidemiology, Institute of Social Medicine, at the Universidade do Estado do Rio de Janeiro, both in Brazil. 
to be realized where governance arrangements are weak. ${ }^{9}$

\section{Background On Brazil}

Brazil provides an important natural experiment with which to examine the role of local health governance on universal health coverage and health outcomes. A national political mandate for the state's role in ensuring universal health coverage was embedded in Brazil's new constitution in 1988. However, the country's size has required major decentralization, which has entailed devolving power for government administration and management, including for the health system, to over five thousand municipalities. ${ }^{12}$ Municipalities in Brazil vary in their population (ranging from approximately 800 to nearly twelve million individuals), size (from 3.6 to over 160,000 square kilometers), and wealth (roughly from R\$3,500 to over R $\$ 700,000$ in per capita 2013 gross domestic product [GDP])..$^{13-15}$ Unsurprisingly, there is also considerable variation in municipalities' health governance, in terms of administrative capacity, leadership, and political will. . $^{17}$

The Estratégia de Saúde da Família (ESF; family health strategy), a community-based primary care program, is the primary vehicle for achieving universal health coverage in Brazil. The program was introduced in 1994 and since has been expanding nationally. It is designed around teams of primary care physicians, nurses, and community health workers, each of which cover approximately a thousand families. The teams provide, free of charge to registered populations, comprehensive primary care, including maternal and child health care, curative care, health promotion and prevention, chronic disease management, home visits, and referrals. ${ }^{18}$ As one of the world's largest primary health care programs,${ }^{19}$ the ESF covered 5,465 of the 5,565 municipalities in Brazil with family health teams that cared for approximately 121.2 million individuals (roughly 62.5 percent of the population) in 2014. Since 1996, municipal governments have been legally responsible for all health care management and financing in their jurisdictions, including the ESF. ${ }^{17}$

Several studies have examined the impact of the ESF and shown that compared to municipalities with lower ESF coverage, those with higher ESF coverage have reduced hospitalizations for ambulatory care-sensitive conditions, ${ }^{20}$ reductions in infant mortality rates, ${ }^{21,22}$ and reductions in cerebrovascular disease mortality rates. ${ }^{23}$ However, no studies have examined the relationship between municipal health governance and ESF performance. We investigated whether ESF expansion has reduced amenable mortality (that is, mortality avoidable through timely and effective health care) rates in Brazil, overall and from different groups of causes, from 2000 to 2012 and if the strength of municipal health governance influenced the change in amenable mortality rates. ${ }^{24}$

\section{Study Data And Methods}

DATA SOURCES For each municipality in Brazil, annual data for the period 2000-12 on mortality, ESF coverage, public health expenditure, socioeconomic characteristics, and population were obtained from the websites of the Brazilian Ministry of Health, ${ }^{25,26}$ Atlas Brazil, ${ }^{27}$ and the Brazilian Institute of Geography and Statistics. ${ }^{28}$ We obtained data from a 2001-02 public administration survey that recorded information about services, policies, and infrastructure provided in municipalities. ${ }^{29}$ Annual municipality ESF coverage is officially calculated as the presence of one ESF team per 3,450 individuals.

AMENABLE AND NONAMENABle MORTALITY Using the criteria of Ellen Nolte and Martin McKee, ${ }^{24}$ we defined amenable mortality as deaths avoidable through the provision of health care for those younger than age seventy-five (for the exact International Statistical Classification of Diseases and Related Health Problems, Tenth Revision [ICD-10], codes, see the online Appendix)..$^{30}$ We defined nonamenable mortality as deaths of people younger than age seventy-five that were not avoidable with health care. Thus, the study population was everyone younger than age seventy-five. To account for changes in demographic characteristics over time, we calculated age-standardized mortality rates for each municipality and year, using population estimates from the census.

\section{Municipality-Level Governance}

To generate a health governance score for municipalities, we used indicators from the public administration survey conducted in 2001-02. ${ }^{28}$ In the absence of an established method for quantifying local governance, we selected indicators according to key dimensions of the WHO's definition of governance, such as government policy guidance, intelligence and oversight, collaboration and coalition building, regulation, and accountability. ${ }^{1}$ We included indicators related to the public administration of health care and local accountability, a concept integral to Brazilian democracy. ${ }^{12}$ We excluded indicators with limited variability across municipalities. Our final measure of health governance was based on eighteen binary indicators (scored 0 
or 1). Scores ranged from 2 to 17; a score of 2 meant that the municipality contained two of the indicator dimensions, and a score of 17 meant that a municipality contained all but one dimension. Municipalities were divided into terciles based on their overall scores. Municipalities in tercile 1 had the lowest health governance scores in 2001-02, while those in tercile 3 had the highest.

We examined factors that were associated with a higher health governance score, including demographic and development factors-notably, population size and education (for a statistical exploration of these factors, see the Appendix). ${ }^{30}$ These factors had only limited explanatory power (because the models did not explain much of the variation in governance scores), which suggests that the governance score captured at least some aspects of governance arrangements and institutional capacity.

covariates Covariates as determinants of mortality were identified from the literature $\mathrm{r}^{31,32}$ and served as proxies for poverty, socioeconomic status, and health service availability. The covariates used in all of the models were non-family medicine doctors per 1,000 population; public hospital beds per 1,000 population; municipality health expenditure per capita ( $\mathrm{R} \$ 100 \mathrm{~s})$; mean household income (R\$100s); fertility rate (mean number of births per woman); and percentages of the population who had a secondary education (for those older than age twenty-five), were unemployed (for those older than age eighteen), had access to piped water and an indoor toilet, were illiterate (for those older than age twentyfive), did not have electricity, and had household garbage collection.

ANALYSIS Longitudinal multivariable regression models, with fixed-effects specifications, are widely used to estimate associations between changes in a variable of interest (for example, ESF coverage) and changes in an outcome (such as mortality). ${ }^{33}$ The models adjust for both observable time-variant confounding factors (for example, changing municipal socioeconomic and demographic characteristics) and unobserved time-invariant characteristics (such as unobservable geographical or sociocultural aspects of municipalities).

Fixed-effects longitudinal (panel) Poisson regression was used to study the association between changes in ESF coverage and changes in rates of both amenable and nonamenable mortality. ${ }^{33}$ A Poisson distribution is appropriate for modeling count data (such as deaths) and allows rates to be used as outcome variables by taking population size into account (for more information on the model specification, see the Appendix)..$^{30}$ The results of such regressions are rate ratios for associations between variables. The rate ratios are interpreted as the ratio between two mortality rates: the modeled mortality rate and the modeled mortality rate when the independent variable is one unit higher (for example, the modeled mortality rate with 0 percent illiteracy and the same rate with 100 percent illiteracy). For simplicity, the difference in the rate ratio from 1 can be considered the percentage change in the mortality rate given a one-unit change in the independent variable.

The unit of analysis was the municipality, and the effect of ESF coverage was estimated for the period 2000-12. Underreporting of deaths in certain municipalities, which has been a problem in Brazil, may be a source of bias. To negate this, we restricted our analysis to 1,622 municipalities, based on the reporting quality of vital statistics. ${ }^{34}$

Municipality-level cluster-robust standard errors were used to adjust for potential heteroskedasticity and autocorrelation. ${ }^{33}$

Age-standardized rates for amenable and nonamenable mortality were the dependent (outcome) variables. The independent variable of interest was ESF coverage (scaled 0 to 1 ), with reported rate ratios based on a one-unit increase (a coverage expansion of 100 percent). An interaction term between ESF coverage and tercile of health governance score was fitted to examine whether associations between ESF coverage and mortality rates varied by tercile. The exhibits show the additional estimated effects for the interaction between governance score terciles and ESF coverage. The overall association reported between ESF coverage and mortality is the estimated effect in tercile 1, but for terciles 2 and 3 the estimated effects are the additional reductions in mortality relative to tercile 1 . However, for simplicity, overall associations between ESF coverage and mortality rates were calculated for each governance score tercile and are reported in the text.

Stata, version 12, was used for our statistical analysis.

SENSITIVITY ANALYSIS Several additional analyses were undertaken to verify the robustness of our findings, including fitting lagged ESF coverage, using variables without data manipulation (including the redistribution of ill-defined deaths to defined causes), excluding ischemic heart disease deaths, not excluding municipalities with inadequate vital statistics reporting, using more indicators in the calculation of a governance score, and using quartiles or quintiles instead of terciles for health governance scores (for the methods and results of these analyses, see the Appendix).$^{30}$ In addition, we used a three-way interaction between terciles of mu- 
nicipality per capita GDP in 2000, terciles of health governance scores, and ESF coverage to investigate whether the scores were acting as a proxy for municipality development or wealth, and if the effect remained after the addition of per capita GDP. Lastly, we used a difference-indifferences methodology to test the robustness of our results with an alternative method.

Limitations Our study had several limitations. First, amenable mortality, as an outcome measure, includes conditions that are treatable in secondary care. Even though we controlled for the availability of local hospitals, the availability and quality of secondary care may have had an impact on our effect estimates.

Second, longitudinal regressions have potential biases, despite being a popular method for evaluating policies. Third, the ecological fallacy may also have affected our estimates, as municipal ESF coverage may not reflect individuals' primary health care coverage or use of care. Fourth, data manipulation could introduce bias, including the redistribution of ill-defined causes of death, age standardization, and extrapolation of covariates.

Fifth, excluding municipalities with inadequate vital statistics reporting could limit the generalizability of our results. Sixth, the data on physician numbers and health expenditures may have issues with reporting quality. Seventh, even though we used a WHO framework ${ }^{1}$ to guide our selection of indicators, our measure of health governance could be a weak reflection of municipalities' actual health governance.

To address these limitations, we adjusted for available covariates, controlled for underlying time trends, and conducted several sensitivity analyses. Results from our sensitivity analyses (see the Appendix) ${ }^{30}$ suggested that our main findings are robust, although the above caveats need to be considered when interpreting our findings.

\section{Study Results}

There was a large variation in the geographical distribution of health governance scores across Brazilian municipalities (Exhibit 1) and in the characteristics of the municipalities that we used as variables in our analysis (Exhibit 2). The mean governance scores were 6.9 (range: 2-8) for municipalities with the lowest governance scores (tercile 1), 9.9 (range: 9-11) for municipalities with medium scores (tercile 2), and 13.0 (range: 12-17) for municipalities with the highest scores (tercile 3).

Across municipalities, socioeconomic variables improved from 2000 to 2012. Municipalities with the highest governance scores (tercile 3) had the largest increase in mean ESF coverage (48.85 percentage points; $p=0.006$ ) and the largest fall in amenable mortality rate $(42.07$ per-

\section{EXHIBIT 1}

Health governance scores of all 5,565 Brazilian municipalities and the 1,622 included in the analysis
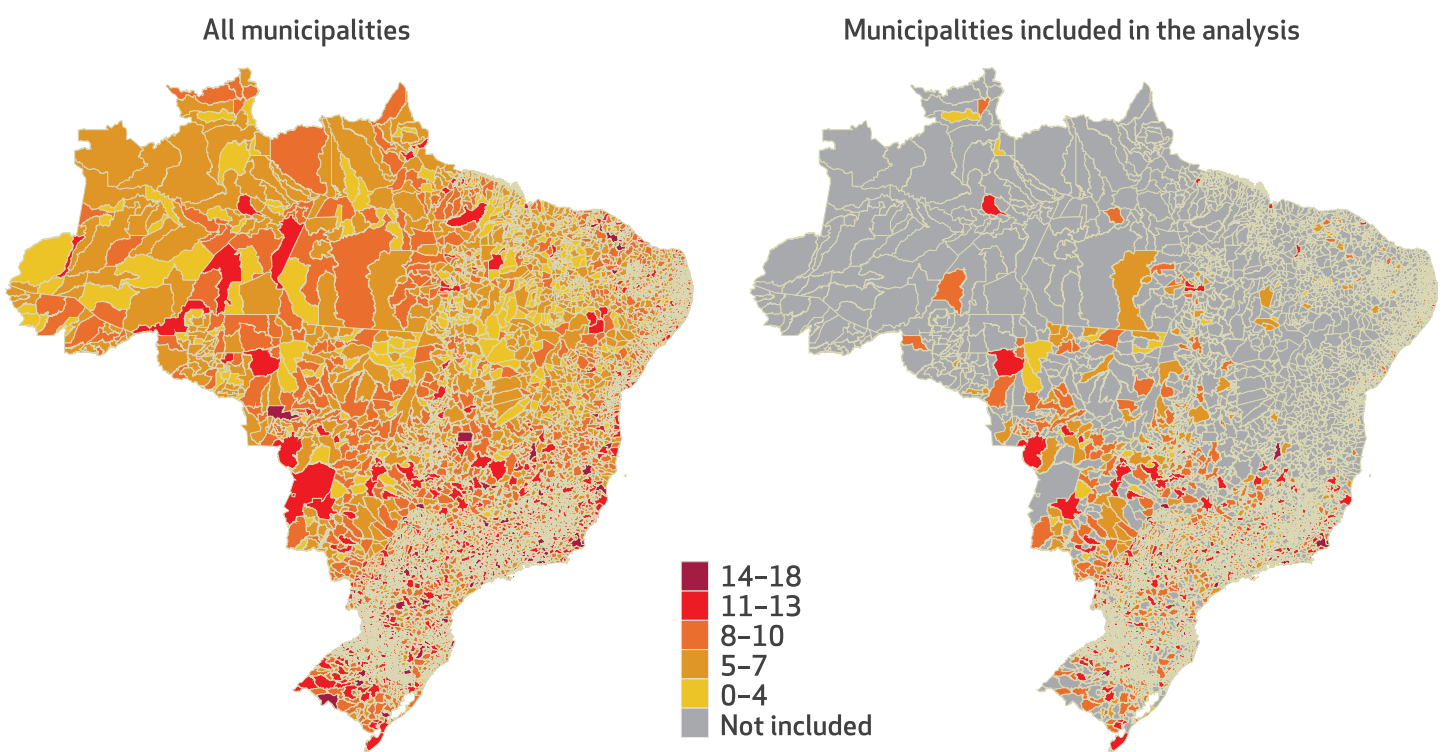

SOURCE Authors' analysis. NOTES As explained in the text, we generated a health governance score for each municipality consisting of eighteen indicators (each scored 0 or 1 ) based on government policy guidance, intelligence and oversight, collaboration and coalition building, regulation, and accountability. Thus, the total score for each municipality ranged from 0 to 18 . In the regression analysis, municipalities were divided into terciles and used in interactions. 


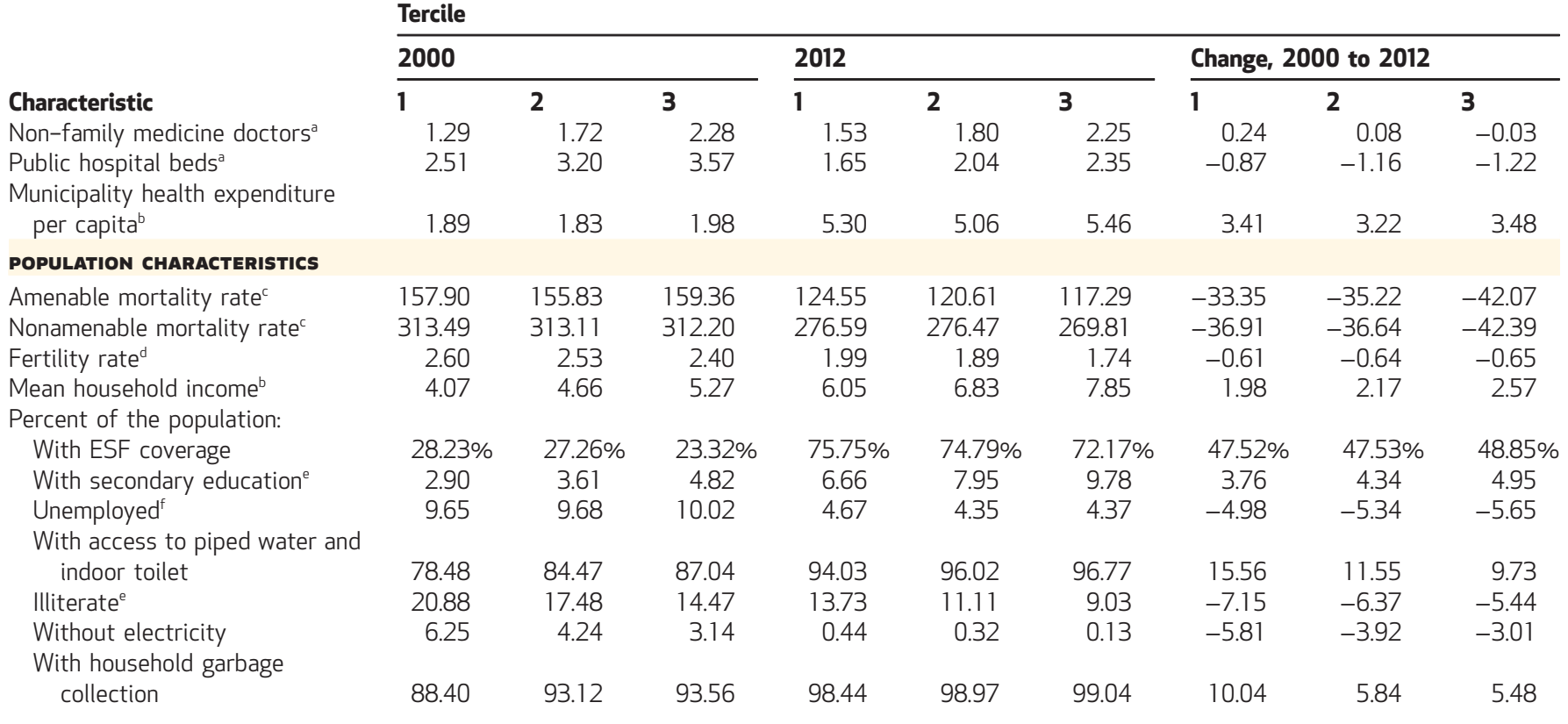

Source Authors' analysis of data from the Brazilian Ministry of Health (see Notes 25 and 26 in text), Atlas Brazil (see Note 27 in text), and the Brazilian Institute of Geography and Statistics (see Notes 28 and 29 in text). Notes Municipalities in tercile 1 had the lowest health governance scores in 2000 (mean score: 6.9 ), while those in tercile 3 had the highest (mean score: 13.04). The mean score for municipalities in tercile 2 was 9.96. ESF is Estratégia de Saúde da Familia (family health strategy), which is explained in the text. R\$ are 2012 Brazilian reals. ${ }^{~} \mathrm{Per} 1,000$ population. ${ }^{\mathrm{b}} \mathrm{R} \$ 100 \mathrm{~s}$. ${ }^{\mathrm{C}} \mathrm{Per} 100,000$ population younger than age seventy-five. Amenable means amenable to health care. ${ }^{\mathrm{d}}$ Mean number of births per woman. ${ }^{\mathrm{e}}$ Among people older than age twenty-five. ${ }^{\mathrm{f}}$ Among people older than age eighteen.

centage points; $p=0.016$ ) (Exhibit 2).

Mortality rates for both amenable and nonamenable causes declined, on average, 1.7 percent (rate ratio: $0.983 ; 95 \%$ confidence interval: $0.976,0.991$ ) from one year to the next (during the period 2000-12) (Exhibit 3). Expansion of ESF coverage (from 0 percent to 100 percent) was associated with a 6.8 percent decline in the amenable mortality rate (rate ratio: 0.932; $95 \%$ CI: $0.908,0.957)$ but was not significantly associated with a change in the nonamenable mortality rate.

In each health governance tercile of municipalities, gaining ESF coverage (a change from 0 percent to 100 percent) was significantly associated with lower amenable mortality rates: The greatest reduction in those mortality rates11.0 percent (rate ratio: 0.890 ; $95 \%$ CI: 0.844 , 0.936 )-occurred in the municipalities with the highest governance scores (tercile 3), calculated as follows. The overall association between a 100 percent increase in ESF coverage and amenable mortality was a rate ratio of 0.957 (Exhibit 4), which is interpreted as a reduction in the mortality rate of 4.3 percent (the result of subtracting the rate ratio of 0.957 from 1 ). This is also the estimate for municipalities in tercile 1 of health governance scores. While there is no sig- nificant additional association between ESF coverage and mortality for tercile 2 (it can be concluded that the reductions are the same as tercile 1), for tercile 3 there was an additional 6.9 percent (a rate ratio of 0.931 ) reduction in the mortality rate from 100 percent ESF expansion. This can be calculated as an overall reduction in tercile 3 as 11.0 percent (the effect sizes are not additive; instead, the rate ratios are multiplicative: $0.957 \times 0.931=0.890$ ).

In municipalities with lower scores (terciles 1 and 2), amenable mortality rates were 4.3 percent (rate ratio: $0.957 ; 95 \%$ CI: $0.927,0.988$ ) and 4.5 percent (rate ratio: 0.955 ; 95\% CI: $0.929,0.982)$ lower, respectively, with full ESF coverage (data not shown). The overall differences between all three terciles were significant $(p=0.042)$, and the difference between the highest and lowest terciles was also significant $(p=0.020)$ (data not shown). ESF coverage was significantly $(p=0.005)$ associated with lower nonamenable mortality rates-a decline of 8.3 percent (rate ratio: 0.917; 95\% CI: 0.865, 0.974 ) - only in the municipalities in tercile 3 (data not shown).

The number of amenable deaths averted was calculated using the estimated sizes of the ESF effect overall and for the highest governance 


\section{EXHIBIT 3}

Associations between municipal-level factors and amenable and nonamenable mortality rates in 1,622 Brazilian municipalities, 2000-12

\begin{tabular}{|c|c|c|}
\hline \multirow[b]{2}{*}{ Factor } & \multicolumn{2}{|l|}{ Rate ratio } \\
\hline & $\begin{array}{l}\text { Amenable } \\
\text { mortality }\end{array}$ & $\begin{array}{l}\text { Nonamenable } \\
\text { mortality }\end{array}$ \\
\hline $\begin{array}{l}\text { Non-family medicine doctors }{ }^{\mathrm{a}} \\
\text { Public hospital beds }{ }^{\mathrm{a}} \\
\text { Municipality health expenditure per capita }\end{array}$ & $\begin{array}{l}0.996 \\
1.008 \cdots \\
1.010 \%\end{array}$ & $\begin{array}{l}1.000 \\
1.001 \\
1.004\end{array}$ \\
\hline $\begin{array}{l}\text { Year } \\
\text { Fertility rate } \\
\text { Mean household income }\end{array}$ & $\begin{array}{l}0.983^{*} \cdots+k \\
0.993 \\
1.000\end{array}$ & $\begin{array}{l}0.983^{* \ldots+k} \\
1.012 \\
0.995\end{array}$ \\
\hline $\begin{array}{l}\text { Percent of the population: } \\
\text { With ESF coverage } \\
\text { Without electricity } \\
\text { With household garbage collection } \\
\text { With access to piped water and an indoor toilet } \\
\text { With secondary education } \\
\text { Unemployed }^{\text {c }} \\
\text { Illiterate }^{c}\end{array}$ & $\begin{array}{l}0.932 \\
0.944 \\
1.067 \\
0.903 \\
0.499 \\
1.421 \\
0.968\end{array}$ & 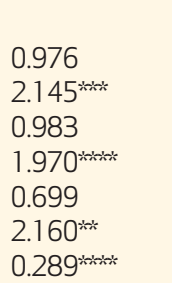 \\
\hline
\end{tabular}

SOURCE Authors' analysis. Notes The exhibit shows results from a fixed-effect panel regression. For example, the association between year and amenable mortality is estimated as a rate ratio of 0.983 and is interpreted as a 1.7 percent reduction (the difference from 1 ) in the mortality rate from one year to the next. Additionally, the association between the percentage of the population without electricity and nonamenable mortality was estimated as a rate ratio of 2.145 and is interpreted as an estimated 114.5 percent increase in the nonamenable mortality rate, should a municipality change from 0 percent to 100 percent of the population without electricity. Robust standard errors were used. There were 21,086 observations for the 1,622 municipalities The fertility rate is the mean number of births per woman. Amenable means amenable to health care. ESF is Estratégia de Saúde da Família (family health strategy), which is explained in the text. R\$ are 2012 Brazilian reals. ${ }^{a}$ Per 1,000 population. ${ }^{b}$ In R\$100s. 'Among people older than

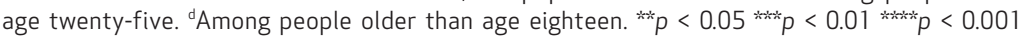

score tercile (for details on the calculations, see the Appendix). ${ }^{30}$ Increasing ESF coverage to 100 percent nationally could lead to 6,400 fewer deaths from amenable causes per year. This figure would increase to 10,400 fewer deaths per year if all municipalities achieved mortality reductions identified in the highest governance score tercile (based on 2012 coverage and mortality rates).

Associations between ESF coverage and amenable mortality by causes were examined (for results, see the Appendix). ${ }^{30}$ ESF expansion was associated with the following lower amenable mortality rates: reductions of 15.2 percent (rate ratio: $0.848 ; 95 \% \mathrm{CI}: 0.787,0.915)$ for infectious diseases, 7.4 percent (rate ratio: 0.926; 95\% CI: $0.860,0.998)$ for perinatal causes, and 5.8 percent (rate ratio: $0.942 ; 95 \%$ CI: $0.916,0.968$ ) for circulatory diseases.

ESF coverage was associated with lower mortality rates only when interacting with governance terciles for infectious diseases (rate ratio: $0.865 ; 95 \%$ CI: $0.777,0.964)$ and circulatory diseases (rate ratio: 0.957; 95\% CI: 0.923, 0.994). Although differences across terciles existed, only the association between ESF coverage and lower mortality rates from circulatory disease was significant overall $(p=0.012)$ when interacting with governance terciles. Expansion to full ESF coverage was associated with a 10.1 percent (rate ratio: 0.899; 95\% CI: 0.859 , 0.942 ) reduction in circulatory disease mortality rates in municipalities in the highest governance tercile, compared to a 4.3 percent (rate ratio: $0.957 ; 95 \%$ CI: $0.923,0.994)$ reduction in those in the lowest tercile.

The results were robust to sensitivity analyses (for results, see the Appendix). ${ }^{30}$ Analyses with lagged and cumulative ESF coverage, without redistribution of ill-defined deaths, and with the removal of 50 percent of ischemic heart disease deaths showed highly comparable results. An analysis that included all municipalities, not just those with adequate vital statistics reporting, showed nonsignificant associations between ESF coverage and mortality rates that most likely were mediated by the association between decreased underreporting of mortality and ESF coverage rates. The mean governance score was slightly higher for municipalities with adequate reporting of vital statistics, compared to all municipalities (9.5 versus 8.2), although the distribution of governance scores across all municipalities was comparable.

Stratifying municipalities into governance score quartiles and quintiles produced similar findings, with higher scores associated with lower mortality rates-although the smaller numbers in these stratifications widened the confidence intervals and produced nonsignificant results in some cases. Using a broader set of variables to create our governance score confirmed our conclusions.

The three-way interaction between governance score terciles, ESF coverage, and terciles of GDP per capita showed concordant results. This analysis tested whether the relationships identified between governance score tercile and ESF coverage from interactions in the models presented above would persist after municipalities were stratified by wealth. While ESF coverage had a differential impact across terciles of GDP (with higher terciles showing greater reductions in amenable mortality), the trends across governance score terciles showing greater reductions in amenable mortality in municipalities with higher governance scores persisted, although they were moderated by GDP. The fact that there were small numbers of municipalities in each stratum widened confidence intervals and limited our ability to make inferences from these results. Had it been possible to take into account both wealth (GDP) and governance with sufficient statistical power, we might have seen smaller effects of governance. Lastly, using 
a difference-in-differences analysis produced comparable results.

\section{Discussion}

Reductions in amenable mortality rates associated with the expansion of primary health care in Brazil through the ESF program between 2000 and 2012 were greatest in municipalities with strong health governance. Although full primary health care coverage was associated with a 6.8 percent reduction in amenable mortality rates on average, there was an 11.0 percent reduction in municipalities with the strongest health governance, compared to a 4.3 percent reduction in municipalities with the weakest health governance. Reductions in overall amenable mortality rates came from lower rates for infectious and circulatory diseases and perinatal causes, although differences across health governance score terciles were found only for deaths from circulatory causes (likely due to the loss of statistical power). We estimate that there would be 4,000 fewer amenable deaths per year in Brazil if all municipalities achieved mortality reductions identified in the highest governance tercile.

Our finding of an aggregate beneficial impact of ESF coverage on amenable mortality rates is consistent with the associations between ESF coverage and reductions in infectious and circulatory disease mortality and child mortality rates found in previous studies. ${ }^{21,23,35}$ We also found reductions in mortality rates with perinatal causes.

The reductions in amenable mortality rates for infectious diseases were much greater than those for noncommunicable diseases (such as circulatory diseases). This is unsurprising, given that many infectious diseases (such as measles, whooping cough, and intestinal infections) are easily prevented or treated in primary health care, and the relationship between primary health care and infectious diseases is well documented in low- and middle-income countries. ${ }^{22,36,37}$ Fewer studies have examined associations between primary health care and mortality from circulatory diseases. ${ }^{23,37}$ Noncommunicable diseases require more complex care than infectious diseases, including interactions with the wider health system, risk factor management, and continuity of care. ${ }^{38}$

The finding that local health governance influences health service effectiveness was anticipated, but it has been documented infrequently. Much of the literature on health governance focuses on decentralization, highlighting associations between increased fiscal flexibility in local governments and more equitable ${ }^{39}$ and respon-

\section{EXHIBIT 4}

Associations between municipal-level factors and amenable and nonamenable mortality rates showing different associations of ESF coverage, by tercile of health governance scores in 1,622 Brazilian municipalities, 2000-12

\begin{tabular}{|c|c|c|}
\hline & \multicolumn{2}{|l|}{ Rate ratio } \\
\hline & $\begin{array}{l}\text { Amenable } \\
\text { mortality }\end{array}$ & $\begin{array}{l}\text { Nonamenable } \\
\text { mortality }\end{array}$ \\
\hline Percent of population with ESF coverage & $0.957 \ldots$ & 0.995 \\
\hline $\begin{array}{l}\text { ESF coverage interaction with: } \\
\text { Tercile } 1 \\
\text { Tercile } 2 \\
\text { Tercile } 3\end{array}$ & $\begin{array}{l}1 \text { (ref) } \\
0.998 \\
0.931^{\kappa \kappa}\end{array}$ & $\begin{array}{l}1 \text { (ref) } \\
1.019 \\
0.922^{* * *}\end{array}$ \\
\hline $\begin{array}{l}\text { Other characteristics } \\
\text { Year } \\
\text { Fertility rate } \\
\text { Mean household income } e^{\mathrm{a}} \\
\text { Non-family medicine doctors } \\
\text { Public hospital beds } \\
\text { Municipality health expenditure per capita }\end{array}$ & $\begin{array}{l}0.982 \ldots \\
0.990 \\
1.002 \\
0.996 \\
1.008 \ldots \\
1.010^{\ldots \ldots}\end{array}$ & $\begin{array}{l}0.982^{\ldots+2 n} \\
1.009 \\
0.998 \\
1.000 \\
1.001 \\
1.004\end{array}$ \\
\hline $\begin{array}{l}\text { Percent of population: } \\
\text { Without electricity } \\
\text { With household garbage collection } \\
\text { With access to piped water and an indoor toilet } \\
\text { With secondary education } \\
\text { Unemployed }^{\text {c }} \\
\text { Illiterate }^{c}\end{array}$ & $\begin{array}{l}0.959 \\
1.060 \\
0.902 \\
0.547 \\
1.356 \\
1.002\end{array}$ & 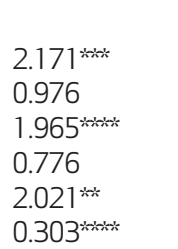 \\
\hline
\end{tabular}

SOURCE Authors' analysis. notes The exhibit shows results from a fixed-effect panel regression. For example, the association between year and amenable mortality is estimated as a rate ratio of 0.982 and is interpreted as a 1.8 percent reduction (the difference from 1) in the mortality rate for each additional year in the study period. The rate ratios from the interaction (between ESF coverage and governance tercile) are interpreted as the additional estimated reductions in mortality in terciles 2 and 3 compared to tercile 1. The overall effect sizes for terciles 2 and 3 are calculated as the product of overall effect for ESF coverage and the tercile-specific effect (for example, for tercile 3 : $0.931 \times 0.957=0.890$ ). Robust standard errors were used. The municipalities in tercile 1 had the lowest health governance scores in 2000, while those in tercile 3 had the highest. There were 21,086 observations for the 1,622 municipalities. Fertility rate is the mean number of births per woman. Amenable means amenable to health care. ESF is Estratégia de Saúde da Família (family health strategy), which is explained in the text. R\$ are 2012 Brazilian reals. ${ }^{a}$ In R\$100s. ${ }^{b}$ Per 1,000 population. 'Among people older than age twenty-five. ${ }^{d}$ Among people older than age eighteen.

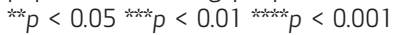

sive $^{40}$ financing-although these associations are less clear in low- and middle-income countries ${ }^{41}$ than in high-income countries.

In Brazil, decentralization (measured by the percentage of ambulatory care facilities controlled by municipalities) has been associated with lower postneonatal mortality rates, which shows that not all municipalities experience the same reductions in mortality and suggests that municipal governments play a role in this heterogeneity. ${ }^{42}$ In Mexico, there is wide variation in the "effective coverage" (the actual gains from coverage) of services across states despite similar per capita spending and national universal health coverage, which implies that local governments play a role in how efficiently resources are used. ${ }^{43}$

Longitudinal regression is a robust methodology widely used in impact evaluations that iden- 
tifies trends and relationships not apparent with the use of other methods. We controlled for underlying time trends and included a wide range of covariates as proxies for social determinants of health and health services. Sensitivity analyses indicated the robustness of our methods.

Using ESF coverage as a continuous variable strengthened the dose-response relationship between primary health care coverage and mortality. We restricted our analyses to municipalities with adequate vital statistics reporting to reduce biases from underreporting of deaths. We excluded municipalities that were more likely to benefit from ESF expansion (those that were relatively poor and had relatively high mortality rates). As a result, if underreporting had not been an issue, we might have found greater effects of ESF expansion. Governance scores in our sample of municipalities with high-quality vital statistics data were slightly higher than in all Brazilian municipalities. Furthermore, excluding municipalities with poor-quality vital statistics reporting removed biases from underreporting of death and increased the level of internal validity of our results.

This article presents the results of the first analysis-to our knowledge-to quantitatively explore the relationship between governance and health services effectiveness. The lower health benefits identified in municipalities with lower health governance may be explained by a number of mechanisms. Inadequate health professional management may result in too few staff members available in clinics, or staff members without appropriate capacity or training to provide high-quality health care. Additionally, weaker oversight of the local health system may create fragmentation of services (for example, between education, community and institutional care, public health, and health services), which could lead to overall inefficiencies, duplication of services, and failure to address the broad social determinants of health. Weaker accountability may mean that funds are inappropriately deployed-either wasted or spent in areas unaligned with local needs. Further research is needed on the role of governance within health systems, including which aspects of governance influence service effectiveness and health outcomes.

\section{Policy Implications}

Consistent with previous literature, ${ }^{20,23,36}$ we found that primary health care played an essential role in reducing deaths amenable to health care in Brazil. This further highlights the importance of investing in primary health care to achieve universal health coverage and improve health outcomes in low- and middle-income settings. The health gains demonstrated can be achieved at low cost, with states and municipalities combined spending approximately US $\$ 90$ per person per year on ESF in $2010 .^{44}$

Our findings nonetheless underline the importance of local governance in optimizing health gains in decentralized health systems. ${ }^{45}$ Brazil is an important setting for analyses of local health governance, since it has recently and rapidly decentralized the health system with a focus on accountability, participation, and democracy in health services. ${ }^{12}$ Within decentralized health systems such as Brazil's, there is potential for national policy fragmentation, local political manipulation, inequities and inefficiencies, and inappropriate resource allocation. ${ }^{17}$ All of these may contribute to weak governance for health and could explain our findings.

It is expected that within highly decentralized systems, this variability in governance can affect service effectiveness. Mechanisms for holding local policy makers and implementers accountable within decentralized systems are essential, as is ensuring that local capacity is sufficient for consistent implementation and management of national health policy. Policy makers and administrators of nationally standardized health programs such as ESF must consider using mechanisms for encouraging local service effectiveness. Possible mechanisms include the benchmarking of service performance and implementing financial incentives for the delivery of consistently high-quality care. A pay-forperformance program was recently introduced in Brazil under the Programa Nacional de Melhoria do Acesso e da Qualidade da Atenção Básica (national program for improving access and quality of primary care). ${ }^{46}$ It links performance on quality indicators (including accessibility, the services and medicines available, health professional training, facilities provided, and satisfaction with care) with ESF team funding, in an attempt to improve the quality of primary care services provided. ${ }^{46}$

The relationship of the wider health system (including secondary health services and community and institutional care) with primary health care and governance arrangements must also be considered. The weaker effects of primary care on noncommunicable diseases, compared to infectious diseases, suggest that improvements to other parts of the health system are necessary for optimal improvements in health outcomes from well-functioning primary care. Furthermore, by strengthening the wider health system, greater gains in health outcomes from stronger governance could be anticipated. 


\section{Conclusion}

Brazil's emphasis on local accountability and decentralization of health services, together with the extensive coverage of one of the largest primary health care programs in the world, provides a unique setting for understanding the variation in effectiveness attributable to local governance for health. Our findings indicate that expanding the provision of primary health care can have a substantial impact on mortality rates, but that strong local governance is essential to the implementation of effective services and the achievement of better health outcomes in terms of reduced amenable mortality rates. There is a need for further research on the role of governance in improving health system effectiveness in low- and middle-income countries to optimize health gains achievable through universal health coverage.
This study was funded partially through Imperial College London, as part of Thomas Hone's PhD program, and partially through the Pan American Health Organization and the Brazilian Ministry of Health, as part of a wider collaborative research program on the Brazilian health system.

\section{NOTES}

1 World Health Organization. Everybody's business: strengthening health systems to improve health outcomes: WHO's framework for action [Internet]. Geneva: WHO; 2007 [cited 2016 Nov 22]. Available from: http://www.who.int/health systems/strategy/everybodys business.pdf

2 Tangcharoensathien V, Mills A, Palu T. Accelerating health equity: the key role of universal health coverage in the Sustainable Development Goals. BMC Med. 2015;13(1):101.

3 World Health Organization. Health systems governance for universal health coverage: action plan [Internet]. Geneva: WHO; c 2014 [cited 2016 Dec 2]. Available from: http:// www.who.int/universal_health_ coverage/plan_action-hsgov_uhc .pdf

4 Savedoff WD. Governance in the health sector: a strategy for measuring determinants and performance [Internet]. Washington (DC): World Bank; 2011 May [cited 2016 Nov 22]. (Policy Research Working Paper No. 5655). Available from: http://documents.worldbank.org/ curated/en/812751468158068363/ pdf/WPS5655.pdf

5 World Health Organization. Health systems: governance [Internet]. Geneva: WHO; c 2016 [cited 2016 Dec 2]. Available from: http://www .who.int/healthsystems/topics/ stewardship/en/

6 Greer SL, Méndez CA. Universal health coverage: a political struggle and governance challenge. Am J Public Health. 2015;105(Suppl 5): S637-9.

7 Wagstaff A, Claeson M. The Millennium Development Goals for health: rising to the challenges [Internet]. Washington (DC): World Bank; c 2004 [cited 2016 Nov 22]. Available from: http://documents .worldbank.org/curated/en/ 875031468329973611/pdf/ 296730PAPEROMilent0goals0for ohealth.pdf
8 Khaleghian P, Das Gupta M. Public management and the essential public health functions. World Dev. 2005;33(7):1083-99.

9 Bardhan P. Decentralization of governance and development. J Econ Perspect. 2002;16(4):185-205.

10 Kickbusch I, Gleicher D. Governance for health in the 21st century [Internet]. Copenhagen: World Health Organization Regional Office for Europe; c 2012 [cited 2016 Nov 22]. Available from: http://www.euro .who.int/_data/assets/pdf_file/ 0019/171334/RC62BD01Governance-for-Health-Web.pdf

11 Atun R, de Andrade LO, Almeida G, Cotlear D, Dmytraczenko T, Frenz P et al. Health-system reform and universal health coverage in Latin America. Lancet. 2015;385(9974): 1230-47.

12 Paim J, Travassos C, Almeida C, Bahia L, Macinko J. The Brazilian health system: history, advances, and challenges. Lancet. 2011; 377(9779):1778-97.

13 Instituto Brasileiro de Geografia e Estatística. Estimativas de população [Internet]. Rio de Janeiro: IBGE; [cited 2016 Dec 2]. Available from: http://www.ibge.gov.br/home/ estatistica/populacao/estimativa 2016/default.shtm

14 Instituto Brasileiro de Geografia e Estatística. Área territorial Brasileira [Internet]. Rio de Janeiro: IBGE; [cited 2016 Dec 2]. Available from: http://www.ibge.gov.br/home/ geociencias/cartografia/default_ territ_area.shtm

15 Instituto Brasileiro de Geografia e Estatística. Produto interno bruto dos municípios [Internet]. Rio de Janeiro: IBGE; [cited 2016 Dec 2]. Available from: http://www.ibge .gov.br/home/estatistica/pesquisas/ pesquisa_resultados.php?id pesquisa $=46$

16 Magalhães R, Senna MdeC. Local implementation of the Family Health Program in Brazil. Cad Saude Publica. 2006;22(12):2549-59.
17 Collins C, Araujo J, Barbosa J. Decentralising the health sector: issues in Brazil. Health Policy. 2000;52(2): 113-27.

18 Harris M, Haines A. Brazil's Family Health Programme. BMJ. 2010; 341(c4945):c4945.

19 Macinko J, Harris MJ. Brazil's family health strategy-delivering community-based primary care in a universal health system. N Engl J Med. 2015;372(23):2177-81.

20 Macinko J, Dourado I, Aquino R, Bonolo Pde F, Lima-Costa MF, Medina MG, et al. Major expansion of primary care in Brazil linked to decline in unnecessary hospitalization. Health Aff (Millwood). 2010; 29(12):2149-60.

21 Aquino R, de Oliveira NF, Barreto ML. Impact of the family health program on infant mortality in Brazilian municipalities. Am J Public Health. 2009;99(1):87-93.

22 Macinko J, Marinho de Souza MdeF, Guanais FC, da Silva Simões CC. Going to scale with communitybased primary care: an analysis of the family health program and infant mortality in Brazil, 1999-2004. Soc Sci Med. 2007;65(10):2070-80.

23 Rasella D, Harhay MO, Pamponet ML, Aquino R, Barreto ML. Impact of primary health care on mortality from heart and cerebrovascular diseases in Brazil: a nationwide analysis of longitudinal data. BMJ. 2014 349:g4014.

24 Nolte E, McKee CM. Measuring the health of nations: updating an earlier analysis. Health Aff (Millwood). 2008;27(1):58-71.

25 Ministério da Saúde Brasil. DATASUS [Internet]. Brasilia: Ministério da Saúde Brasil; c 2016 [cited 2016 Dec 2]. Available from: http:// datasus.saude.gov.br/informacoesde-saude/tabnet

26 Ministério da Saúde Brasil, Departamento de Atenção Básica. Histórico de Cobertura da Saúde da Família [Internet]. Brasilia: DAB; 2012 [cited 2016 Dec 2]. Available from: http:// 
dab.saude.gov.br/portaldab/ historico_cobertura_sf.php

27 Atlas do Desenvolvimento Humano no Brasil. Database [Internet]. Brasilia: The Atlas; [cited 2016 Dec 2] Available from: http://www .atlasbrasil.org.br/2013/en/ download/

28 Instituto Brasileiro de Geografia e Estatística. Pesquisa de Assistência Médico-Sanitária [Internet]. Rio de Janeiro: IBGE [cited 2016 Dec 2] Available from: http://www.ibge gov.br/home/estatistica/ populacao/condicaodevida/ams/ 2009/

29 Instituto Brasileiro de Geografia e Estatística. Perfil dos municípios Brasileiros [Internet]. Rio de Janeiro: IBGE; [cited 2016 Dec 2]; Available from: http://www.ibge .gov.br/home/estatistica/economia/ perfilmunic/2001/default.shtm

30 To access the Appendix, click on the Appendix link in the box to the right of the article online.

31 Belon AP, Barros MB, Marín-León L. Mortality among adults: gender and socioeconomic differences in a Brazilian city. BMC Public Health. 2012;12(1):39.

32 Goldani MZ, Barbieri MA, Bettiol H, Barbieri MR, Tomkins A. Infant mortality rates according to socioeconomic status in a Brazilian city. Rev Saude Publica. 2001;35(3): 256-61.

33 Wooldridge JM. Introductory econometrics: a modern approach. 5th ed. Mason (OH): Cengage
Learning; 2013.

34 De Andrade CL, Szwarcwald CL. Socio-spatial inequalities in the adequacy of Ministry of Health data on births and deaths at the municipal level in Brazil, 2000-2002. Cad Saude Publica. 2007;23(5):1207-16. Portuguese.

35 Rasella D, Aquino R, Barreto ML. Impact of the Family Health Program on the quality of vital information and reduction of child unattended deaths in Brazil: an ecological longitudinal study. BMC Public Health. 2010;10:380.

36 Rasella D, Aquino R, Barreto ML. Reducing childhood mortality from diarrhea and lower respiratory tract infections in Brazil. Pediatrics. 2010;126(3):e534-40.

37 Macinko J, Starfield B, Erinosho T. The impact of primary healthcare on population health in low- and middle-income countries. J Ambul Care Manage. 2009;32(2):150-71.

38 Beaglehole R, Epping-Jordan J, Patel V, Chopra M, Ebrahim S, Kidd M, et al. Improving the prevention and management of chronic disease in low-income and middle-income countries: a priority for primary health care. Lancet. 2008; 372(9642):940-9.

39 Bossert TJ, Larrañaga O, Giedion U, Arbelaez JJ, Bowser DM. Decentralization and equity of resource allocation: evidence from Colombia and Chile. Bull World Health Organ. 2003;81(2):95-100.

40 Faguet J-P. Does decentralization increase government responsiveness to local needs? Evidence from Bolivia. J Public Econ. 2004;88(3-4): 867-93.

41 Robinson M. Does decentralisation improve equity and efficiency in public service delivery provision? IDS Bull. 2007;38(1):7-17.

42 Guanais FC, Macinko J. The health effects of decentralizing primary care in Brazil. Health Aff (Millwood). 2009;28(4):1127-35.

43 Lozano R, Soliz P, Gakidou E, Abbott-Klafter J, Feehan DM, Vidal $C$, et al. Benchmarking of performance of Mexican states with effective coverage. Lancet. 2006; 368(9548):1729-41.

44 Servo LMS, de Paiva AB. Gasto com atenção básica das três esferas de governo: possibilidades e limitações das análises a partir de bases de dados orçamentário-financeiras [Spending on primary care by the three levels of government: possibilities and limitations from analyzing financial budget databases]. Brasília: Instituto de Pesquisa Econômica Aplicada; 2013.

45 Rocha Filho Fdos S, da Silva MC. [Costs with personnel and productivity analysis of family health program teams in Fortaleza, Ceará]. Cien Saude Colet. 2009;14(3): 919-28. Portuguese.

46 Fontenelle LF. [Recent changes in the National Primary Care Policy: a critical appraisal]. Revista Brasiliera de Medicina de Família e Comunidade. 2012;7(22):5-9. Portuguese. 